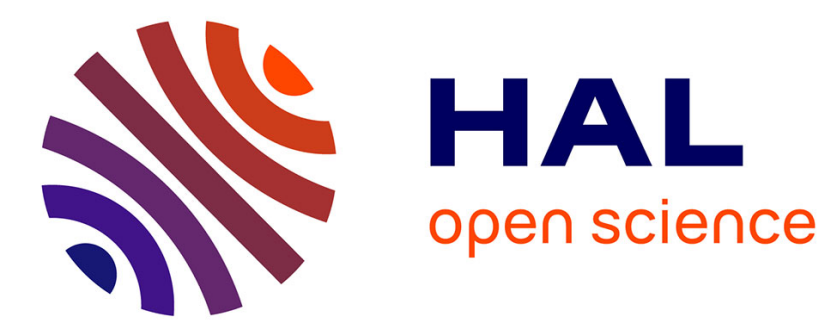

\title{
How I managed to hide my shadow \\ Roberto Casati
}

\section{To cite this version:}

Roberto Casati. How I managed to hide my shadow. Perception, 2007, pp.000-000. ijn_00171289v2

\section{HAL Id: ijn_00171289 \\ https://hal.science/ijn_00171289v2}

Submitted on 12 Sep 2007

HAL is a multi-disciplinary open access archive for the deposit and dissemination of scientific research documents, whether they are published or not. The documents may come from teaching and research institutions in France or abroad, or from public or private research centers.
L'archive ouverte pluridisciplinaire HAL, est destinée au dépôt et à la diffusion de documents scientifiques de niveau recherche, publiés ou non, émanant des établissements d'enseignement et de recherche français ou étrangers, des laboratoires publics ou privés. 


\title{
How I managed to hide my shadow
}

\author{
Roberto Casati \\ [Dec. 31, 2006; version of Mar 26, 2007] \\ Institut Jean Nicod EHESS ENS CNRS, Paris, \\ and Università IUAV, Venice
}

\begin{abstract}
A special type of visual stimulus is described which gives the perceiver the impression that a shadow has been hidden behind a surface in the image, contrary to expectations based on ecological situations in which covering a shadow only passes it on to the cover.
\end{abstract}

Keywords: shadow perception; shadow character

I have always been intrigued by the extraordinary attempts (anecdotally reported, and experienced at home) by children to hide their or their friends' cast shadow by laying objects of various types on it: sheets of paper, of cardboard, or sand or gravel. The result is of course not up to children's expectations. As the shadow caster is not removed, the shadow is simply transferred to the superposed obtruder; it is impossible to hide. It appears thus that a basic rule of the ecology of shadows is that "the cast shadow of an object $a$ cannot be hidden by another object $b$ covering the shadow of a". (See fig. 1.II. and 1.III.; legend is provided by the schema in fig. 1.I) The qualification 'another' is meant to rule out the simple case in which an object can hide its own shadow by laying on it (as when one sleeps on the ground).

Although the rule is generally valid, can we engineer a stimulus which appears to falsify it? That is to say, can there be an illusion of shadow hiding such as the one represented in fig 1.IV? Some standard figural conditions should be taken into account in order to convey the impression of an object being visually occluded by another. But on top of that, the candidate should be such as to attenuate part of the illumination boundary determined by the shadow the shadow caster $a$, and to simultaneously enhance part of the reflectance boundary of the obtruder $b$. (See fig. 1.I.) Now, manipulating the texture, the color or the lightnessof the shaded area (of all and only the area shadowed by $a$ ) can in some cases destroy the shadow character. Most likely, this depends on the fact that the visual system binds together the features of darkness and of the introduced modification, thereby forbidding the shadow interpretation. The binding is a consequence of the fact that the features in question are spatially congruent. The inference is that "it is unlikely that a shadow exactly matches a previously existing textural, color or lightness accident, hence it is likely that this dark area is not a shadow".

The trick is then to have the shadow of object $a$ partly covered by an object $b$ possessing a different texture than the background onto which the shadow of $a$ is cast; and then to have another shadow (say, from an extra object $c$ ) cast precisely onto the shape of $b$. In such a case, 
the shadow of $a$ will appear to pass under object $b$, so that it will not be 'transferred' to $b$. In other words, $b$ will (surprisingly) appear to be unaffected by the shadow of $a$. This is because the shadow character of the shadow cast on $b$ has been destroyed by the spatially coincident features of $b$. Part of the shadow cast on $b$ is the shadow cast by $a$. The destruction of shadow character applies thus to that part. Hence the region of $b$ that is shaded by $a$ will not appear to be shaded. The illumination boundary has been eliminated by the shadow cast by $c$; and the surface boundary has been enhanced by the texture of object $b$. (See fig. 1.IV.)

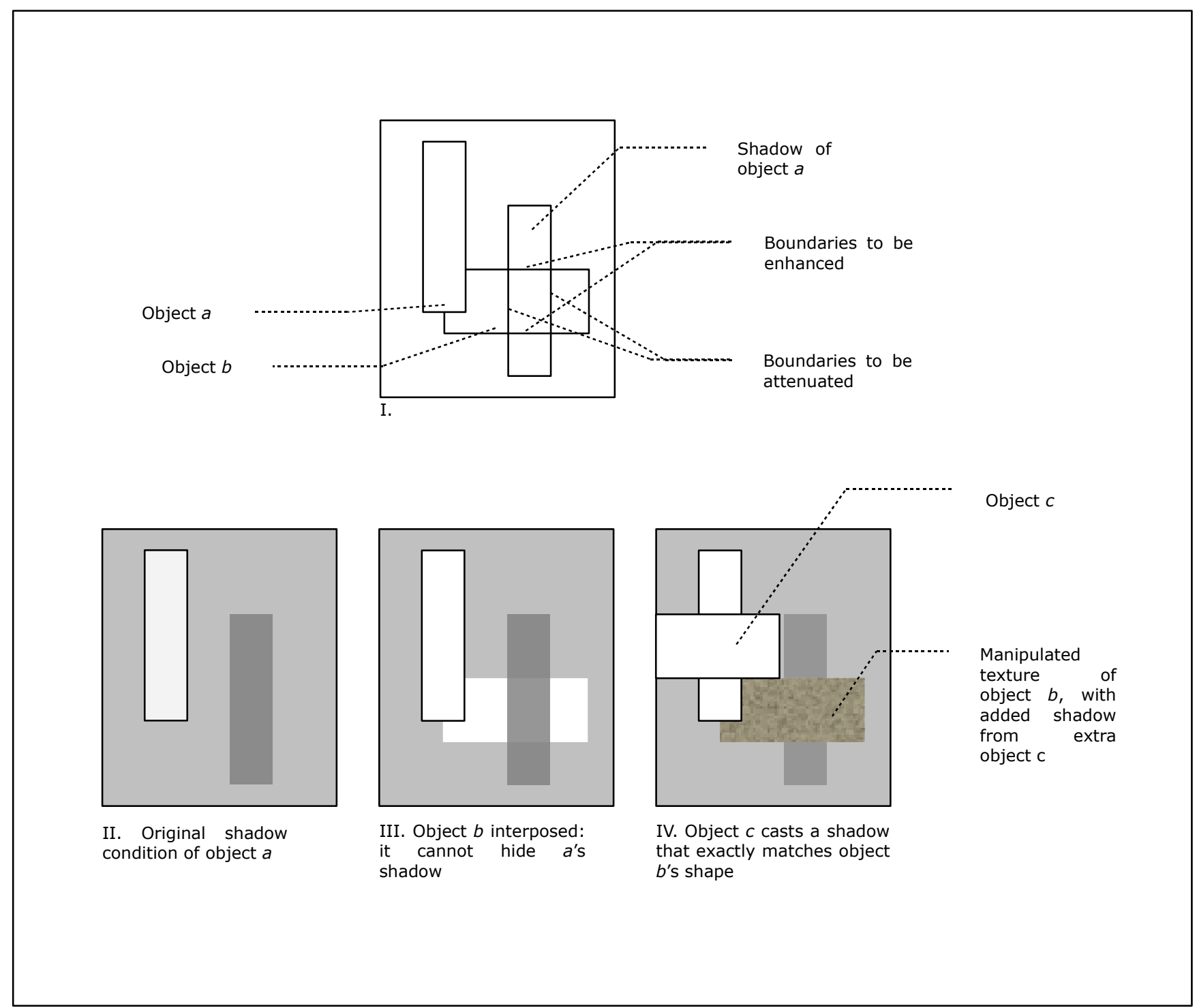

Fig. 1. Conditions for visually hiding a shadow behind an object.

Can this be seen in real life? A vivid ecological example of the situation described above is depicted in fig. 2. Here the area (the surface of a "virtual" object $b$ ) corresponding to the shadow of the toboggan (the toboggan, partly visible at the fore, occupies the role of object $c$ ) is lighter than the shadow of $a$ (the author) because of the night freeze. 


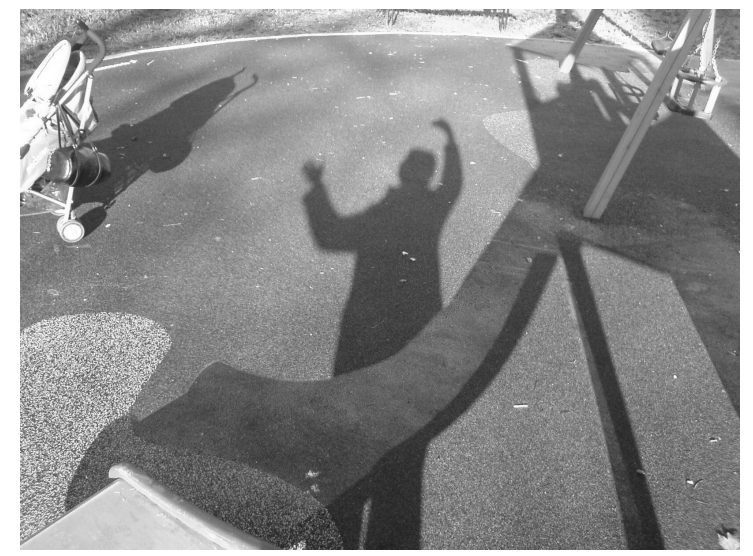

Fig. 2. Ice on the shadow of the toboggan hides the author's shadow. Picture by Roberto Casati.

The author's shadow can thus appear to pass under object $b$, leaving it unscathed. The whole situation is possible because a large shadow from a tall building has just cleared the ground, allowing the sun to melt the freeze but for the areas shaded by the toboggan. The author has come to the scene a few minutes after the sun has arrived, as is inferable from the fact that the rightmost border of the frozen area has been "left behind" by the shadow that in meantime has moved because of the sun's movement relative to the toboggan.

A home-made stimulus is reproduced in Fig 3. The shadow of the coffee-mill has been covered with semolina pellets (the ones used for couscous). The shadow of a bar (object $a$ ) appear thus to pass under the spread of pellets (object $b$ ) thanks to the assisting shadow of the coffee-mill (object $c$ ). 


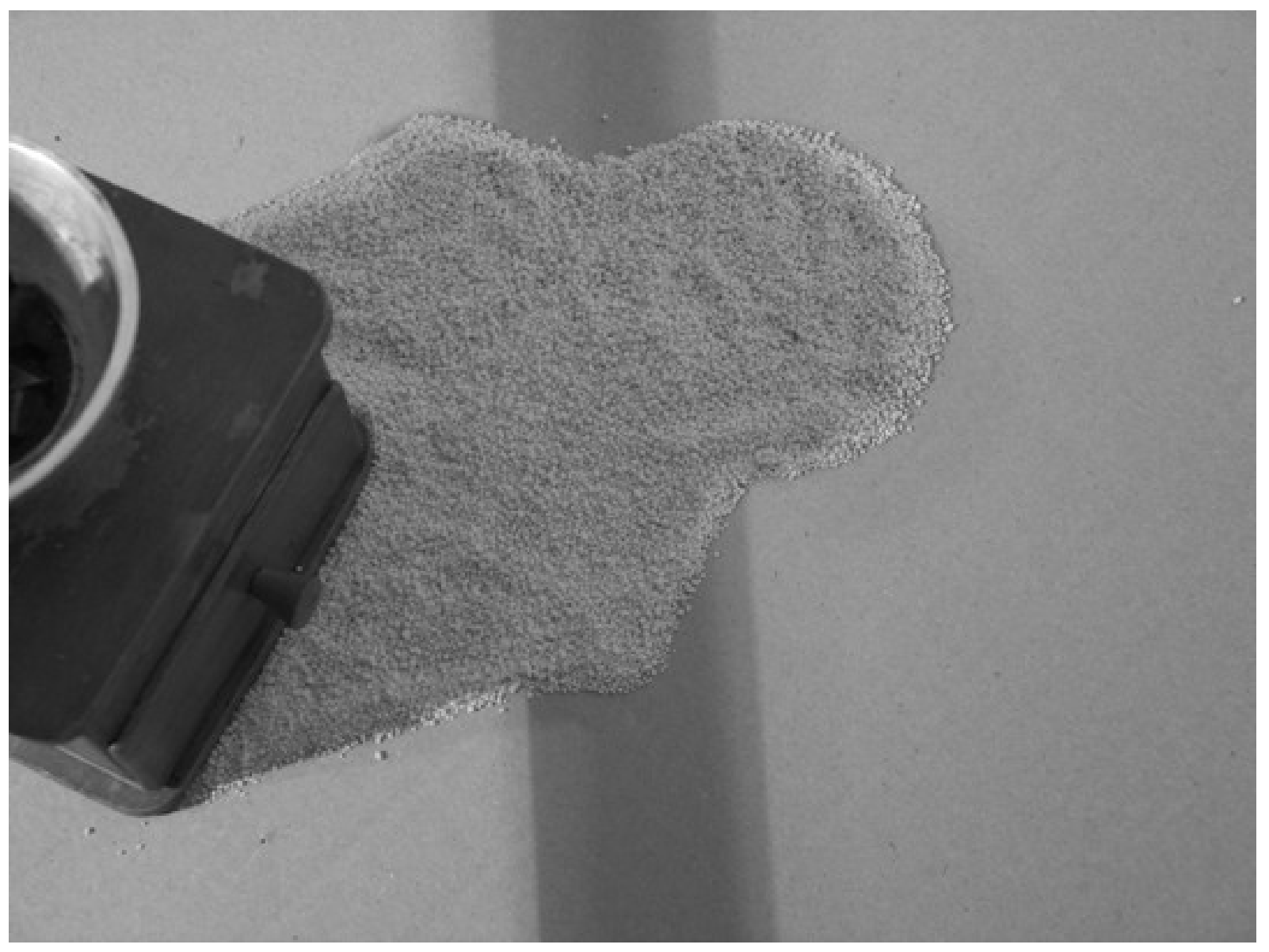

Fig. 3. Coucous hides the shadow of a bar. Picture by Marco Bacci. 


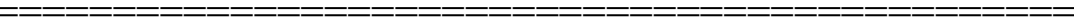

Colour picture for web edition:

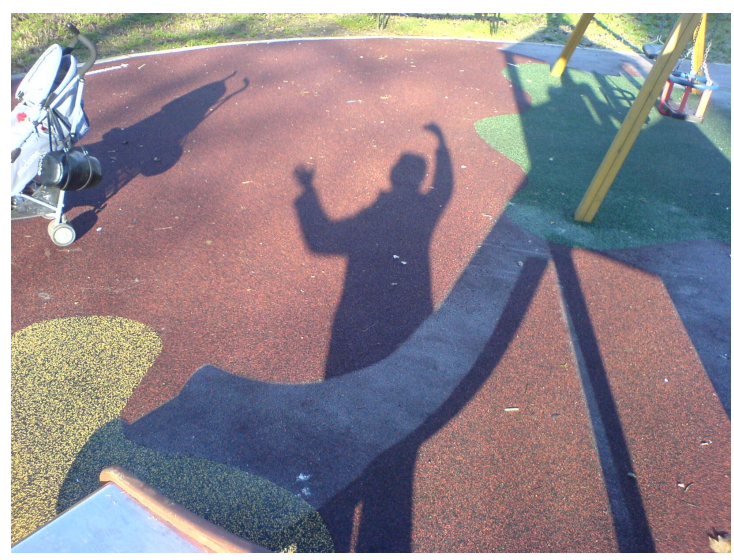

